(2) Open Access Full Text Article

\title{
Intravitreal bevacizumab alone or combined with triamcinolone acetonide as the primary treatment for diabetic macular edema
}

This article was published in the following Dove Press journal:

Clinical Ophthalmology

2I July 20II

Number of times this article has been viewed

\author{
Hatem M Marey \\ Amin F Ellakwa \\ Ophthalmology Department, \\ Minoufiya University, Egypt
}

Correspondence: Hatem M Marey Ophthalmology Department, Minoufiya University, Egypt, 14 Naeem St, East Bank, Shebin El Koom, Minoufiya, Egypt Tel +20 I6 3252918

Email hatemmarey@yahoo.com
Purpose: To compare the efficacy of intravitreal injection of bevacizumab alone or combined with intravitreal triamcinolone as the primary treatment for cases with diabetic macular edema (DME).

Methods: Ninety eyes were enrolled in one of the three study arms; where intravitreal triamcinolone acetonide (IVT) was used in group I, IVT/intravitreal bevacizumab (IVT/IVB) in group II, and IVB in group III. The visual acuity (VA) and central macular thickness (CMT) were used as the outcome measures, where the results of each group were calculated and compared with the results of the other.

Results: There was significant improvement in the VA in the three study groups at weeks 6 and 12; with regards to the intraocular pressure (IOP), there was significant difference at week 6 in the IVT and IVT/IVB groups, and at week 12 in IVT/IVB group, and nonsignificant difference at week 6 in the IVB group and at week 12 in IVT and IVB groups.

Conclusion: From this study, we conclude that IVB is an effective drug for treatment of DME, and has a long lasting effect when compared with IVT and when compared with combined IVT/IVB; adding IVT does not affect the outcome measures except for elevating the IOP in treated patients in the early post-injection period.

Keywords: visual acuity, central macular thickness, intraocular pressure, IVT, IVB

\section{Introduction}

Diabetic macular edema (DME) is a leading cause of visual impairment in diabetic patients, ${ }^{1}$ and its prevalence has been reported to be $10 \%{ }^{2}$

The Early Treatment Diabetic Retinopathy Study showed that macular laser photocoagulation (MPC) is effective in reducing the risk of visual loss in eyes with clinically significant macular edema. ${ }^{3}$

However, the improvement in visual acuity occurs in only about $17 \%$ of treated eyes, and cases show three lines of improvement in visual acuity, and MPC results in laser scars that tend to increase with time, thus decreasing the likelihood of visual improvement, ${ }^{3}$ and laser treatment has limited results in eyes with diffuse DME. ${ }^{3,4}$

Intravitreal triamcinolone (IVT) shows to have a beneficial effect on DME, 5,6 with a probable mechanism of increase in tight junction proteins, which diminish vessel leakage by a local vasoconstrictive effect, ${ }^{7,8}$ and angiostatic properties through inhibition of vascular endothelial growth factor (VEGF), ${ }^{9}$ but the treatment success is limited by ocular complications. ${ }^{10-15}$

Recent research has revealed the role of VEGF in inducing vascular hyperpermeability. ${ }^{16-20}$ 
Bevacizumab, a humanized full-length monoclonal antibody that inhibits all isoforms of VEGF, has been used for DME. ${ }^{21}$

In this randomized, three-arm clinical trial, we compared the efficacy of intravitreal injection of bevacizumab (IVB) alone or combined with IVT as the primary treatment of cases with DME.

\section{Patients and methods}

This prospective study included 90 eyes of 90 different patients with clinically significant macular edema based on the Early Treatment Diabetic Retinopathy Study definitions, ${ }^{1}$ after being approved by the Ethics committee board of Minoufiya University. Patients were divided randomly into three study groups: group I (IVT), group II (IVT/IVB), and group III (IVB). Each group included 30 eyes, and all cases were followed up for 12 weeks.

Exclusion criteria were: previous laser treatment, previous intraocular injection, previous intraocular surgery, history of glaucoma or ocular hypertension, and significant media opacity.

Complete ocular examination in the form of measurement of the best corrected visual acuity, intraocular pressure (IOP), slit lamp biomicroscopy, funduscopy, and central macular thickness (CMT) measurement using optical coherence tomography (Stratus OCT, version 4.0.7, Carl Ziess Meditec Inc, Jena, Germany).

Intravitreal injections were performed under complete sterile conditions using bovidine iodine $10 \%$ for eyelid skin and 5\% for ocular surface wash, then after complete draping, surface anesthesia was applied and intravitreal injection was performed as follows: for group I (IVT), $0.1 \mathrm{~mL}$ (4 mg) triamcinolone (Kenacort-A, SmithKline Beecham, an affiliated company to GalaxoSmithKline, London, UK) was injected in the inferotemporal quadrant; for group II (IVT/IVB), $1.25 \mathrm{mg}$ bevacizumab in $0.05 \mathrm{~mL}$ (Avastin; Gemetech Inc, San Fransisco, CA), which was previously prepared in 27-gauge sterilized needle, was injected in the superotemporal quadrant, and $2 \mathrm{mg}$ triamcinolone $0.05 \mathrm{~mL}$ was injected in the inferotemporal quadrant using 27-gauge needle in the same sitting; for group III (IVB), $1.25 \mathrm{mg}$ bevacizumab in $0.05 \mathrm{~mL}$ was injected in the inferotemporal quadrant; for complete masking, a needleless syringe was pressed against the globe at the superotemporal quadrant in groups I and III; and all injections were done once and not repeated in the follow-up period.

Examination of best corrected visual acuity, IOP, detection of anterior chamber reaction, lens opacity, and funduscopy were performed at day 1, and weeks 1, 6, and 12 after injection; and detection of macular thickness in $1 \mathrm{~mm}$ circle centered around the fovea was done at the week 6 and week 12 follow-up.

Topical mixed antibiotics and steroids (tobramycin $0.3 \%$ and dexamethazone $0.1 \%$ ) were applied for 1 week, and topical $\beta$-blocker was used to control the IOP at or below $22 \mathrm{~mm} \mathrm{Hg}$ in the early post-injection period.

Change in the best corrected visual acuity and CMT were taken as the outcome measures, and complications from intravitreal injection were recorded.

Statistical analysis was performed using SPSS Statistics version 10 (IBM Corporation, Somers, NY) software, where descriptive measures were used for the pre- and postinjection data; paired $t$-test was used to detect the statistical difference between the pre- and the post-injection data; one-way ANOVA (analysis of variance) test was used to detect the statistical difference in the outcome measures at weeks 6 and 12; and the least significant difference post hoc test was used to detect the statistical difference between the results of each pair of the study groups at the week 6 and week 12 follow-up.

\section{Results}

For all the study patients, the mean age was $57.64 \pm 7.23$ years, with a minimum of 43 and maximum of 76 years; males were 53 (58.89\%), and females were 37 (41.11\%); patients with proliferative diabetic retinopathy (PDR) were $46(51.11 \%)$, and those with nonproliferative diabetic retinopathy (NPDR) were 44 (48.89\%).

For group I (IVT), the mean age was $57.67 \pm 7.19$ years, with a minimum of 43 and maximum of 76 years; males were $18(60 \%)$, and females were 12 (40\%); patients with PDR were 14 (46.67\%), and those with NPDR were 16 (53.33\%).

For group II (IVT/IVB), the mean age was $57 \pm 7.44$ years, with a minimum of 45 years and a maximum of 75 years; males were 19 (63.33\%), and females were 11 (36.67\%); patients with PDR were $18(60 \%)$, and those with NPDR were $12(40 \%)$.

For group III (IVT), the mean age was $57 \pm 7.3$ years with a minimum of 44 and a maximum of 73 years; males were $16(53.33 \%)$, and females were 14 (46.67\%); patients with PDR were 20 (66.67\%), and those with NPDR were $10(33.33 \%)$, demographic and clinical features of the study groups are shown in Table 1.

The descriptive data of the pre-injection visual acuity, IOP, and CMT results, and those at week 6 and 12 post-injection in the three study groups were recorded as shown in Table 2. 
Table I Demographic and clinical features of the study groups

\begin{tabular}{|c|c|c|c|c|c|c|}
\hline \multirow[t]{2}{*}{ Group } & \multirow[t]{2}{*}{ Number } & \multirow{2}{*}{$\frac{\text { Age }}{\text { Mean } \pm \text { SD }}$} & \multicolumn{2}{|c|}{ Gender } & \multicolumn{2}{|c|}{ Diabetic retinopathy } \\
\hline & & & Male & Female & PDR & NPDR \\
\hline Group I & 30 & $57.66 \pm 7.19$ & 18 & 12 & 14 & 16 \\
\hline Group II & 30 & $57.66 \pm 7.44$ & 19 & 11 & 12 & 18 \\
\hline Group III & 30 & $57.60 \pm 7.30$ & 16 & 14 & 20 & 10 \\
\hline Total & 90 & $57.64 \pm 7.23$ & 53 & 37 & 46 & 44 \\
\hline
\end{tabular}

Abbreviations: PDR, proliferative diabetic retinopathy; NPDR, nonproliferative diabetic retinopathy; SD, standard deviation.

Comparing the pre-injection to the post-injection results at weeks 6 and 12 with regards to visual acuity, IOP, and CMT in the three study groups revealed the following.

- Group I (IVT). With regards to the visual acuity, there was high significant difference between the pre- and postinjection results at week $6(P=0.001)$; however, this difference was only significant at week $12(P=0.015)$. With regards to the IOP, there was a high significant difference between the pre- and post-injection results at week 6 $(P=0.001)$; however, the difference was not significant at week $12(P=0.227)$. With regards to the CMT, there was a high significant difference between the pre- and post-injection results at weeks 6 and $12(P=0.001$, and $P=0.003$, respectively).

- Group II (IVT/IVB). With regards to the visual acuity, there was a high significant difference between the preand post-injection results at weeks 6 and $12(P=0.001$ for both). With regards to the IOP, there was a high significant difference between the pre- and post-injection results at week $6(P=0.001)$; however, the difference was only significant at week $12(P=0.019)$. With regards to the CMT, there was a high significant difference between the pre- and post-injection results at weeks 6 and 12 $(P=0.001$ for both).

- Group III (IVB). With regards to the visual acuity, there was a high significant difference between the pre- and post-injection results at week 6 and $12(P=0.001$ for both). With regards to the IOP, there was no significant difference between the pre- and post-injection results at weeks 6 and $12(P=0.258$ and $P=0.169$, respectively). With regards to the CMT, there was a high significant difference between the pre- and the post-injection results at weeks 6 and 12 ( $P=0.001$ for both). See Table 3 .

Two cases in group I and one case in group II had IOP greater than $22 \mathrm{~mm} \mathrm{Hg}$ for which topical $\beta$-blockers were used for 2 weeks, minimal anterior chamber reaction was detected in one case in groups I and II that resolved within 1 week without extra new medications, neither cataracts nor other complications were noted in the follow-up period in all the study groups.

Comparing the visual acuity results at week 6 between the three study groups, there was no significant difference $(P=0.151)$, and also between each pair of the three study groups; however, at week 12, there was high significant difference $(P=0.004)$, and between each pair, there was high significant difference between groups I and II $(P=0.001)$, significant difference between groups I and III $(P=0.039)$, and no significant difference between groups II and III $(P=0.201)$.

Comparing the CMT results at week 6 between the three study groups, there was no significant difference $(P=0.121)$, and between each pair of the three study groups, there was significant difference between groups II and III only $(P=0.04)$; however, at week 12 , there was high significant difference $(P=0.001)$, and between each pair, there was high significant difference between groups I and II $(P=0.001)$, significant difference between groups I and III $(P=0.009)$, and no significant difference between groups II and III $(P=0.287)$. These results are shown in Tables 4 and 5.

Table 2 Descriptive statistics of pre- and post-injection data in the three study groups

\begin{tabular}{lccc}
\hline Variable & Group I & Group II & Group III \\
\hline VA & & & \\
Before & $0.18 \pm 0.12$ & $0.19 \pm 0.13$ & $0.22 \pm 0.12$ \\
6 weeks & $0.21 \pm 0.11$ & $0.23 \pm 0.13$ & $0.25 \pm 0.13$ \\
I2 weeks & $0.20 \pm 0.10$ & $0.33 \pm 0.17$ & $0.28 \pm 0.13$ \\
IOP & & & \\
Before & $14.83 \pm 2.34$ & $15.67 \pm 2.86$ & $15.47 \pm 2.93$ \\
6 weeks & $16.97 \pm 2.47$ & $17.80 \pm 2.48$ & $15.63 \pm 2.62$ \\
I2 weeks & $15.03 \pm 2.09$ & $15.07 \pm 2.05$ & $15.13 \pm 2.21$ \\
CMT & & & \\
Before & $492.30 \pm 145.91$ & $477.70 \pm 153.38$ & $445.06 \pm 123.87$ \\
6 weeks & $463.20 \pm 124.16$ & $444.66 \pm 131.94$ & $410.70 \pm 106.24$ \\
I2 weeks & $471.53 \pm 148.44$ & $348.80 \pm 113.25$ & $383.83 \pm 115.42$ \\
\hline
\end{tabular}

Note: Values are mean \pm standard deviation.

Abbreviations: VA, visual acuity; IOP, intraocular pressure; CMT, central macular thickness. 
Table 3 Paired sample test comparing pre- and post-injection data in the three study groups

\begin{tabular}{|c|c|c|c|}
\hline \multirow[t]{2}{*}{ Variable } & \multicolumn{3}{|c|}{ Significance (two-tailed) } \\
\hline & Group I & Group II & Group III \\
\hline VA pre- and post-injection at 6 weeks & 0.001 & 0.001 & 0.000 \\
\hline VA pre- and post-injection at 12 weeks & 0.015 & 0.000 & 0.000 \\
\hline IOP pre- and post-injection at 6 weeks & 0.000 & 0.000 & 0.258 \\
\hline IOP pre- and post-injection at 12 weeks & 0.227 & 0.019 & 0.169 \\
\hline CMT pre- and post-injection at 6 weeks & 0.000 & 0.000 & 0.001 \\
\hline CMT pre- and post-injection at 12 weeks & 0.003 & 0.000 & 0.000 \\
\hline
\end{tabular}

Abbreviations: VA, visual acuity; IOP, intraocular pressure; CMT, central macular thickness.

\section{Discussion}

Intravitreal injections are commonly used for treatment of DME. In this study we evaluated the results of both drugs used in the study, alone or combined, and compared the results to reach the best intravitreal drug that can be used safely and has the longest duration of action.

At week 6 , there was a high significant improvement in visual acuity with all the study groups, and at week 12 , this high significant improvement was maintained in the IVB and IVT/IVB groups only; this is similar to the results of Soheilian et $\mathrm{al}^{22}$ in 2007 ; however, in the IVT group this high significant improvement was not maintained.

IVT alone had improved the visual acuity of the treated patients at week 6 , but this level was not maintained at week 12, which gives IVB an upper hand over IVT for treatment of DME with regard to the longer duration of action.

With regards to the IOP, there was a high significant increase at week 6 in the IVT and IVT/IVB groups, and this increase was maintained in the IVT/IVB group but at a low level at week 12; however, in the IVB group, there was no significant increase in the IOP at weeks 6 and 12, which adds to the drawbacks of IVT alone or when combined with IVB, making IVB alone more safe. IOP elevation with IVT was also documented in other studies. ${ }^{10-15}$

The increase in the IOP in the IVT/IVB and IVT groups could be attributed in part to the relatively large volume of intravitreal injection $(0.1 \mathrm{~mL})$ compared with the $0.05 \mathrm{~mL}$ volume of injections in the IVB group.

With regards to the CMT, there was a high significant decrease in the CMT at weeks 6 and 12 in all the study groups. This is similar to the results of Soheilian et $\mathrm{a}^{22}$ in 2007 (where they had a significant improvement of the CMT at week 6 in the IVB and the IVT/IVB groups) and to the results of Ahmadieh et $\mathrm{al}^{23}$ in 2008 (where they had significant improvement in the CMT at weeks 6 and 12 in the IVB and IVT/IVB groups). However, the mean CMT for the IVT group was more at week $12(471.33 \mu \mathrm{m})$ compared with that at week $6(463 \mu \mathrm{m})$, and for groups II and III the CMT was lower at week 12 than at week 6 . This maintained decrease in the CMT at week 12 in groups II and III was attributed to bevacizumab; however, IVT alone showed a greater increase in CMT at week 12 than at week 6.

IVB has an upper hand in its maintained effect on visual acuity, and CMT improvement at week 12, a benefit that could not be achieved by IVT alone. Also, the hazard of

Table 4 ANOVA test for the post-injection data in the three study groups

\begin{tabular}{|c|c|c|c|c|}
\hline & Variable & Sum of squares & Mean square & Significance \\
\hline \multirow[t]{3}{*}{ VA 6 weeks post-injection } & Between groups & $8.745 \mathrm{E}-02$ & $4.372 \mathrm{E}-02$ & 0.151 \\
\hline & Within groups & 1.966 & $2.260 \mathrm{E}-02$ & \\
\hline & Total & 2.053 & & \\
\hline \multirow[t]{3}{*}{ CMT 6 weeks post-injection } & Between groups & 57474.200 & 28737.100 & 0.121 \\
\hline & Within groups & II 54499.400 & 13270.108 & \\
\hline & Total & 1211973.600 & & \\
\hline \multirow[t]{3}{*}{ VA I 2 weeks post-injection } & Between groups & 0.244 & 0.122 & 0.004 \\
\hline & Within groups & 1.814 & $2.085 \mathrm{E}-02$ & \\
\hline & Total & 2.058 & & \\
\hline \multirow[t]{3}{*}{ CMT I 2 weeks post-injection } & Between groups & 239820.956 & 119910.478 & 0.001 \\
\hline & Within groups & | 397254.433 & 16060.396 & \\
\hline & Total & 1637075.389 & & \\
\hline
\end{tabular}

Abbreviations: ANOVA, analysis of variance; VA, visual acuity; CMT, central macular thickness. 
Table 5 Multiple comparisons between the post-injection data in the three study groups using the least significance difference test

\begin{tabular}{llll}
\hline Dependent variable & $\begin{array}{l}\text { Compared } \\
\text { groups }\end{array}$ & Significance \\
\hline VA 6 weeks post-injection & 1 & 2 & 0.310 \\
& 1 & 3 & 0.347 \\
& 2 & 3 & 0.052 \\
CMT 6 weeks post-injection & 1 & 2 & 0.302 \\
& 1 & 3 & 0.300 \\
VA I2 weeks post-injection & 2 & 3 & 0.040 \\
& 1 & 2 & 0.001 \\
CMT I2 weeks post-injection & 1 & 3 & 0.039 \\
& 2 & 3 & 0.201 \\
& 1 & 2 & 0.000 \\
& 1 & 3 & 0.009 \\
& 2 & 3 & 0.287 \\
\hline
\end{tabular}

Abbreviations: VA, visual acuity; CMT, central macular thickness.

elevating the IOP, especially at week 6 , adds to the drawbacks of IVT in the treatment of DME.

Comparing the three study groups with regards to the two outcome measures, visual acuity and CMT, we found no difference at week 6 ; however, at week 12 , there was high significant difference between the three study groups, which supports the idea of having a better intravitreal drug. This is against the results of Ahmadieh et $\mathrm{a}^{23}$ in 2008, who found no significant difference in the CMT and visual acuity between the IVB and the IVB/IVT groups.

On comparing the results of the outcome measures for each pair of drugs, we found that there was a significant difference in the maintained improvement in visual acuity and the decrease in the CMT at week 12 on using IVB alone or combined with IVT. While this significant difference was not observed with IVT alone, this confirms the better and maintained effect of IVB over IVT in the treatment of DME without additional benefit of combining IVT to IVB.

We conclude that IVB is an effective drug for treatment of DME and has a long-lasting effect compared with IVT and combined IVT/IVB. Adding IVT does not affect the outcome measures except for elevating the IOP in treated patients in the early post-injection period; however, the maintained effect of these intravitreal drugs needs long-term follow-up studies.

\section{Disclosure}

The authors report no conflicts of interest in this work.

\section{References}

1. Klein R, Klein BE, Moss SE. Visual impairment in diabetes. Ophthalmology. 1984;91:1-9.

2. Hardy RA, Crawford JB. Retina. In: Vaughn D, Asbury T, Riordan-Eva P, editors. General Ophthalmology. 15th ed. Stamford, CT: Appleton and Lange; 1999:178-199.
3. Early Treatment Diabetic Retinopathy Study Research Group. Photocoagulation for diabetic macular edema. Early treatment diabetic retinopathy study report number 1. Arch Ophthalmol. 1985;103: 1796-1806.

4. Lee CM, Olk RJ. Modified grid laser photocoagulation for diffuse diabetic macular edema: long-term visual results. Ophthalmology. 1991; 98:1594-1602.

5. Sutter FK, Simpson JM, Gillies MC. Intravitreal triamcinolone for diabetic macular edema that persists after laser treatment: threemonth efficacy and safety results of a prospective, randomized, double-masked, placebo-controlled clinical trial. Ophthalmology. 2004;111:2044-2049.

6. Audren F, Erginay A, Haouchine B, et al. Intravitreal triamcinolone acetonide for diffuse diabetic macular oedema: 6-month results of a prospective controlled trial. Acta Ophthalmol Scand. 2006;84: 624-630.

7. Chun DW, Heier JS, Topping TM, et al. A pilot study of multiple intravitreal injections of ranibizumab in patients with center-involving clinically significant diabetic macular edema. Ophthalmology. 2006;113:1706-1712.

8. Sears JE, Hoppe G. Triamcinolone acetonide destabilizes VEGF mRNA in Muller cells under continuous cobalt stimulation. Invest Ophthalmol Vis Sci. 2005;46:4336-4341.

9. Gardner TW, Antonetti DA, Barber AJ, et al. Penn State Retina Research Group. Diabetic retinopathy: more than meets the eye. Surv Ophthalmol. 2002;47:S253-S256.

10. Shulman S, Ferencz JR, Gilady G, Ton Y, Assia E. Prognostic factors for visual acuity improvement after intravitreal triamcinolone injection. Eye (Lond). 2007;21(8):1067-1070.

11. Tewari HK, Sony P, Chawla R, et al. Prospective evaluation of intravitreal triamcinolone acetonide injection in macular edema associated with retinal vascular disorders. Eur J Ophthalmol. 2005;15: 619-626.

12. Gregori NZ, Rosenfeld PJ, Puliafito CA, et al. One-year safety and efficacy of intravitreal triamcinolone acetonide for the management of macular edema secondary to central retinal vein occlusion. Retina. 2006;26:889-895.

13. Konstantopoulos A, Williams CP, Newsom RS, Luff AJ. Ocular morbidity associated with intravitreal triamcinolone acetonide. Eye (Lond). 2007;21(3):317-320.

14. Ricci F, Missiroli F, Parravano M. Argon laser trabeculoplasty in triamcinolone acetonide induced ocular hypertension refractory to maximal medical treatment. Eur J Ophthalmol. 2006;16:756-757.

15. Thompson JT. Cataract formation and other complications of intravitreal triamcinolone for macular edema. Am J Ophthalmol. 2006;141:629-637.

16. Aiello LP, Avery RL, Arrigg PG, et al. Vascular endothelial growth factor in ocular fluid of patients with diabetic retinopathy and other retinal disorders. $N$ Engl J Med. 1994;331:1480-1487.

17. Funatsu H, Yamashita H, Ikeda T, et al. Vitreous levels of interleukin-6 and vascular endothelial growth factor are related to diabetic macular edema. Ophthalmology. 2003;110:1690-1696.

18. Funatsu H, Yamashita H, Ikeda T, et al. Angiotensin II and vascular endothelial growth factor in the vitreous fluid of patients with diabetic macular edema and other retinal disorders. Am J Ophthalmol. 2002;133:537-543.

19. Qaum T, Xu Q, Joussen AM, et al. VEGF-initiated blood-retinal barrier breakdown in early diabetes. Invest Ophthalmol Vis Sci. 2001;42:2408-2413.

20. Tolentino MJ, Miller JW, Gragoudas ES, et al. Intravitreous injections of vascular endothelial growth factor produce retinal ischemia and microangiopathy in an adult primate. Ophthalmology. 1996;103: $1820-1828$

21. Cunningham ET Jr, Adamis AP, Altaweel M, et al. Macugen Diabetic Retinopathy Study Group. A Phase II randomized double-masked trial of pegaptanib, an anti-vascular endothelial growth factor aptamer, for diabetic macular edema. Ophthalmology. 2005;112:1747-1757. 
22. Soheilian M, Ramezani A, Bijanzadeh B, et al. Intravitreal bevacizumab (avastin) injection alone or combined with triamcinolone versus macular photocoagulation as primary treatment of diabetic macular edema. Retina. 2007;27:1187-1195.
23. Ahmadieh H, Ramezani A, Shoeibi N, et al. Intravitreal bevacizumab with or without triamcinolone for refractory diabetic macular edema; a placebo-controlled, readomized clinical trial. Graefes Arch Clin Exp Ophthalmol. 2008;246:483-489.

\section{Publish your work in this journal}

Clinical Ophthalmology is an international, peer-reviewed journal covering all subspecialties within ophthalmology. Key topics include: Optometry; Visual science; Pharmacology and drug therapy in eye diseases; Basic Sciences; Primary and Secondary eye care; Patient Safety and Quality of Care Improvements. This journal is indexed on
PubMed Central and CAS, and is the official journal of The Society of Clinical Ophthalmology (SCO). The manuscript management system is completely online and includes a very quick and fair peer-review system, which is all easy to use. Visit http://www.dovepress.com/ testimonials.php to read real quotes from published authors. 